\title{
YOUTH HEALTH SMARTPHONE APPLICATION "TEENFIT" IN INCREASING ADOLESCENT KNOWLEDGE ABOUT ANEMIA, IN BANTUL, YOGYAKARTA
}

\author{
Tuti Rohani, Hartono, Muhammad Akhyar, Sri Mulyani \\ Master in Development and Community Empowerment, \\ Universitas Sebelas Maret, Surakarta
}

\begin{abstract}
Background: The prevalence of anemia in women of reproductive age (15 - 49 years) has increased every year. Lack of knowledge of adolescents about anemia is a major problem of non-adherence to taking iron supplements. Cellular technology-based knowledge enhancement intervention is the "TEENFIT" application. Researchers designed this health smartphone application containing material on anemia, knowledge, attitudes, and behavior of drinking iron supplements, an alarm that serves as a reminder to take iron supplements, a report that contains reports on all activities of adolescents taking iron supplements. This study aimed to examine the the use of youth health smartphone application "TEENFIT" in increasing adolescent knowledge about anemia, in Bantul, Yogyakarta.
\end{abstract}

Subjects and Method: A randomized control trial conducted in Bantul, Yogyakarta, from June to August 2020. A sample of 95 adolescents was randomized into two groups: (1) Experiment group that used the youth health smartphone application "TEENFIT, and (2) Control group that received no intervention. The dependent variable was knowledge about anemia. The independent variable was youth health smartphone application "TEENFIT". The data were collected using questionnaire. The data were analyzed by independent t-test.

Results: After the intervention, knowledge about anemia in the experimental group (Mean=77.31; $\mathrm{SD}=6.60$ ) was higher than the control group (Mean=67.55; $\mathrm{SD}=5.60)$, and it was statistically insignificant $(\mathrm{p}=0.266)$.

Conclusion: Knowledge about anemia in adolescents increases with the using of youth health smartphone application "TEENFIT", but it is not statistically significant.

Keywords: health application, knowledge, anemia, adolescents

\section{Correspondence:}

Tuti Rohani. Master in Development and Community Empowerment, Universitas Sebelas Maret. Jl. Ir. Sutami 36A, Surakarta 57126, Central Java. Email: tuti.rohani8o@gamil.com. Mobile: +62818460097 . 